\title{
Mediatizaciones: hacia la consolidación de un campo de estudios
}

\section{PORSANDRA VALDETTARO}

sandravaldettaro@gmail.com Universidad Nacional de Rosario (UNR), Argentina. Directora del Centro de Investigaciones en Mediatizaciones (CIM) www.cim.unr.edu.ar

Al ritmo de la creciente complejidad de los procesos comunicativos actuales, el campo de estudios de mediatizaciones ha logrado, durante los últimos años, una creciente consolidación en elámbito académico a nivel global. Ello se expresa en la creación de centros de investigación dedicados al tema, cátedras universitarias, publicaciones indexadas, programas de estudio de posgrado. Esta progresiva institucionalidad indica la constitución de un área investigativa cuyas fronteras se encuentran demarcadas por un estilo transdisciplinar que incluye variados enfoques, los cuales, de manera dialógica y también controversial, abordan nuestra contemporaneidad bajo el supuesto general de la mediatización como una dimensión antropológica y técnica que determina el funcionamiento de todas las esferas sociales.

Elcarácter nuclear del debate sobrelas mediatizacionesenlasciencias actuales -tanto en las sociales, como en las humanas y en las llamadas ciencias duras- es el motivo que convoca al presente volumen de InMediaciones de la Comunicación, el cual está dedicado a presentar un estado de la cuestión que, aunque de manera aproximativa, logra, creemos, dar cuenta de la situación general del campo.

Los textos que acá se ofrecen son, por lo tanto, una muestra de la diversidad de enfoques y objetos que sobre el tema circulan a nivel global, y, simultáneamente, una estrategia de puesta en común dela producción deinvestigadores procedentes de distintas tradiciones teóricas e institucionales, a los fines de establecer un lazo intelectualquese sostieneen variaslenguas-en español, en inglés, en portugués-y que se hace cargo del carácter políglota de la cultura académica. Pensado desde Uruguay, el volumen convoca no sólo a aquello que se dirime en la producción académica e investigativa rioplatense o brasileña, sino que también se aproxima a territorios de Europa y de América del Norte, dando cuenta de una circulación intelectual cuya mejor marca continúa siendo el cosmopolitismo.

El estudio de las mediatizaciones no podría no ser global e internacionalista, ya que su naturaleza sistémica es, a su vez, clave interpretativa de cualquier 
color local. Este volumen, en tanto texto, produce, de tal modo, en su propio despliegue, un efecto de unidad de sentido sobre el tópico de la mediatización que se constituye, a su vez, en operatoria política de consolidación de un campo de estudios de vital trascendencia en el área de la comunicación.

Los textos acá presentados y la procedencia de sus autores indican la presencia de por lo menos tres grandes núcleos teóricos en el estudio de las mediatizaciones: la escuela nórdica, la escuela de Toronto y la escuela sociosemiótica.

Por un lado, el artículo de Stig Hjarvard -de la Universidad de Copenhague, en Dinamarca- es representativo de la llamada "escuela nórdica de la mediatización”. El texto se inscribe en una genealogía que enlaza -en muchos de sus términos- con la crítica a los estudios sobre efectos de la comunicación, encarados ahora de manera compleja, transdisciplinaria y bajo una mirada sistemática, en la cual la mediatización adquiere un carácter de condición estructural de interdependencia con los procesos sociales, culturales e institucionales. El artículo es la versión en español del reciente texto de Hjarvard publicado en inglés por Wiley, en 2016, en The International Encyclopedia of Media Effects, editado por Patrick Roessler y Liesbet van Zoonen. En sintonía con los planteos de Krotz (2014) -otro delosprincipales exponentes dela "escuela nórdica"-la mediatización constituye, para Hjarvard, una "respuesta académica" que, sobre los finales del último siglo, se hace cargo de la creciente implantación de los medios digitales y los cambios correlativos en los medios masivos: ello supone un reencuadre del objeto de estudio, tomando en cuenta la plena integración de los medios al entramado cultural y social. De tal modo, desde su punto de vista, la agenda de estudios de medios y comunicación se torna más especializada y diversa: alertando en relación con el riesgo de desintegración y fragmentación del campo que dicha especialización pudiera ocasionar, Hjarvard propone los estudios en mediatización como un intento para sintetizar dichos desarrollos mediante una estrategia investigativa que necesariamente debe plantearse como interdisciplinaria.

Otro de los enfoques sobre la mediatización se encuentra en la contribución de Paolo Granata, investigador del McLuhan Center de la Universidad de Toronto, Canadá. El artículo parte de una perspectiva antropológica de la mediatización en términos de proceso cultural, proponiendo una reevaluación de una figura clave de la investigación en comunicación, Edward T. Hall (19142009), y su noción de ecología intercultural. La idea de cultura en la obra de Hall tiene sus raíces en la capacidad humana para interactuar con su entorno mediante su transformación a través del tiempo, a partir de sus "extensiones", que se transmiten socialmente. Esta perspectiva se ubica en la tradición canónica de la definición de cultura propuesta en 1871 por Edward B. Tylor.

En el enfoque de Hall que reconstruye Granata queda clara la visión crítica de la mediatización en tanto proceso cultural complejo. Se ponen en juego supuestos del relativismo lingüístico y el materialismo cultural en línea con la in- 
vestigación antropológica deEdward Sapiry Benjamin Whorf, lo cual se enlaza con la tradición de Boas. Este concepto de cultura, estrictamente "ecológico", se vincula tanto a una visión sistémica como cognitivista, y sería retomado por la Escuela de Toronto. En tal sentido, el artículo de Granata constituye una contribución significativa a los fines de reconstruir los supuestos a partir de los cuales Marshall McLuhan adoptaría el concepto de los media como "extensiones", a partir de los trabajos de Hall y de Buckminster Fuller, al tiempo que expone los fundamentos de la mediatización como "ecología" de la Escuela de Toronto.

Por su parte, en lo que respecta a la denominada "escuela sociosemiótica" -de cuño peirceano y, específicamente, veroniano-, varios son los artículos de este volumen que recuperan y problematizan el núcleo crítico acerca de las mediatizaciones y sus implicancias en la vida social.

José Luis Fernández - de la Universidad de Buenos Aires, Argentina- presenta en su artículo un análisis sobre las transformaciones de los objetos de estudio, ligado a fenómenos actuales que implican un posicionamiento en distintas temporalidades y espacialidades: haciendo eje en la convivencia entre actividades multimediáticas y prácticas interaccionales -tanto novedosas como delarga tradición-. En su artículo, Fernández describelos modos en que algunas redes sociales se van convirtiendo en "complejas plataformas multimedia". El enfoque sociosemiótico se articula con una mirada interdisciplinaria, lo cual permite abordar el vínculo entre distintos sistemas de intercambio como un espacio tensional entre plataformas y acciones discursivas "micro", a los fines de evaluar las llamadas nuevas mediatizaciones. Asimismo, recuperandola noción de socialidad por plataformas de Van Dijck (2013), Fernández se detiene en modos particulares de intercambio discursivo entre mediatizaciones networking y postbroadcasting, interrogando los niveles de novedad en la compleja articulación entre lo micro y lo macro, entre lo interindividual y lo masivo. De tal modo, basculando entre la sociosemiótica, el análisis del discurso y la pragmática, el artículo de Fernández es, además de un aporte teórico obligatorio, una convocatoria a la responsabilidad crítica de las instituciones académicas que implica, necesariamente, asumir una mirada interdisciplinar.

Del mismo modo se ubica el artículo de Antonio Fausto Neto, investigador perteneciente a la Universidad de Vale do Rio dos Sinos (Unisinos), Brasil. En este trabajo la perspectiva veroniana se articula con investigaciones previas del autor, quien de manera sistemática viene abordando el fenómeno actual de la "circulación" en sus distintas dimensiones. Como Presidente del Centro Internacional de Semiótica e Comunicação (CISECO), con sede en Brasil, la figura de Fausto Neto se proyecta como uno de los referentes principales de la Escuela Sociosemiótica. En este volumen él presenta un trabajo que forma parte de los resultados del proyecto de investigación "Circulação: Gênese, Funcionamento e Complexificação das 'Zonas de Contato' na Sociedade em Midiatização" (CNPQ/Unisinos), el cual aborda el estudio del proceso 
de impeachment a la presidente de Brasil, Dilma Rousseff, en un ambiente de circulación mediatizada, enfatizando el carácter de procesualidad de las operaciones discursivas más allá delasfronteras delas distintas esferas sociales.

La transdisciplinariedad a la que acude la sociosemiótica se advierte claramente en otro de los artículos provenientes de Brasil: el de Moisés Sbardelotto, también de la universidad Unisinos. A partir del análisis de la página Diversidade Católica en Facebook, Sbardelotto se propone detectar las huellas de las transformaciones del catolicismo en la cultura contemporánea. Retomando la "perspectiva de largo plazo" de la mediatización postulada por Verón (2014) -ya que, como plantea el autor, desde sus propios orígenes el catolicismo se caracterizó por una voluntad comunicacional específica-, Sbardelotto aborda la pluralización de la religiosidad en la mediatización digital contemporánea. En tal contexto, hipotetiza que la visibilización de la población homosexual promovería una homoafectividad tanto en la sociedad como en el ámbito eclesial, en sintonía con lo que el Papa Francisco llama "periferias existenciales". Vía digitalización, estaría ocurriendo, según Sbardelotto, un "giro copernicano" en la Iglesia, que se advierte en los desvíos de lo religioso y en los "poli-sistemas mediático-religiosos emergentes", los cuales tienden a ampliar las ciudadanías religiosas. Además de subrayar en su artículo las complejidades actuales entre lo sacro y la civis, Sbardelotto propone un peculiar experimento argumentativo que se despliega en la articulación entre la sociosemiótica y la escuela nórdica, ya que, tal como postula el autor, a los fines de estos análisis se hace necesario detenerse tanto en el meta-proceso comunicacional de cada fase histórica según el postulado de Krotz (2007), como en las relaciones de dependencia/subordinación entre religión y medios, de acuerdo a la perspectiva de Hjarvard (2013).

El punto de vista histórico es central, también en el artículo presentado por Sebastián Stra -investigador de la Universidad Nacional de Rosario (UNR), Argentina-. Su trabajo constituye un avance de resultados de investigación sobre prácticas de escucha de radio, entre 1920 y 1950, en la ciudad de Rosario. El artículo fue escrito a partir de abordajes sociosemióticos, discursivos y de historia delos medios. Bajola presunción de que dichas prácticas se constituyen en condiciones específicas para el recuerdo, se aborda el relato de los oyentes como materialidad significante en sus múltiples dimensiones. El abordaje de los "testimonios" se realiza mediante una articulación específica entre memoria y discurso, que se instala en el desafío que supone pensar la radio como "medio de masas", esto es, como un dispositivo diferenciado de construcción de memoria en el contexto del pasaje de la radio de aficionado a la radio broadcasting. Ello implica una modalidad particular de organizar la información; la imposibilidad de registro y conservación del contenido; y la fusión de las posiciones enunciativas en una misma temporalidad. En general, como sostiene el artículo, se entiende que dicho fenómeno sucede hasta la invención del grabador casero que permitió el registro de las emisiones en la década del 
60 del siglo pasado. La cuestión central del "archivo" -y su peculiar función en la cultura- constituye un tópico central derivado del texto de Stra, que las investigaciones sobre historia de los medios van desbrozando paulatinamente. Un dato a confrontar es, por ejemplo, el que hace constar Mónica Berman en su tesis doctoral de la UBA (2013), quien refiere que los radioteatros en Argentina se empiezan a grabar muy tempranamente y sus registros son enviados a las provincias, hecho que se interrumpe cuando la Sociedad General de Autores de la Argentina (Argentores) advierte que les "pierde el rastro". Esta cuestión le impide cobrar derechos y devela las particulares relaciones entre prácticas de escucha, archivo e industria. Este dato histórico -nada menor- no obstaculiza el planteo general de la investigación de Stra y equipo, que se ubica en el contexto de lo que Lucia Santaella (2003) define como la transición de una cultura de broadcasting a una "cultura das mídias", es decir, la transición a una lógica distinta a la cultura de masas que, al calor de las innovaciones técnicas, produce una creciente individualización del consumo. El artículo de Stra se detiene específicamente en las circunstancias previas a dicha transición, en la cual el testimonio es huella, básicamente, de una "experiencia" dela fascinación con los dispositivos que antecede a la era del registro.

Otros temas de actualidad son abordados, desde un punto de vista preeminentemente sociosemiótico, en otros artículos de este volumen de InMediaciones de la Comunicación. El artículo presentado por Luis Baggiolini y Sebastián Castro Rojas -ambos investigadores de la UNR, Argentina-analiza las modalidades de apropiación de los lenguajes multiplataforma por parte de los candidatos en las campañas presidenciales de 2011 y 2015 en Argentina. Triangulando una perspectiva cuantitativa sobre el uso de Twitter con un análisis crítico-interpretativo del contenido de los tweets de campaña, el artículo aborda la conformación de lenguajes híbridos, intertextuales, universos narrativos y nuevas subjetividades colectivas en el ecosistema digital. A partir de un repaso histórico desde la video-política de los años 90 del siglo pasado, bajo reinado televisivo, hasta el uso de las redes por parte de Barak Obama en las presidenciales de EE.UU. en 2008, y teniendo en cuenta las experiencias globales de movilizaciones masivas vía redes sociales, el artículo se posiciona en los estudios de webpolítica, política 2.0 o tecnopolítica. El fenómeno de los fans acude también al análisis como clave interpretativa del comportamiento de los seguidores -suscriptores, gusteadores, etcétera- de los candidatos políticos en las redes sociales, en una complejización de la figura del "prodestinatario" planteada por Verón en 1996. Otra de las nociones puesta al servicio de la investigación es la de "cámara de eco", de la que habló V. O. Key en 1966, idea que refiere al modo en que los votantes repiten el discurso político de las élites. Los retweets - plantean los autores siguiendo a Calvo (2015)- pueden ser pensados a partir de dicho concepto. Entre los géneros convocados para analizar estos microrrelatos se encuentran el spot publicitario y el videoclip musical, 
con sus características de brevedad, calidad de edición e impacto emocional; pero formando parte de una macroestructura narrativa en la cual el tópico de la fuerza da continuidad y coherencia, así como los mitos fundantes de lo popular del primer gobierno peronista en Argentina (1946-1955) asegurarían, en palabras de los autores, la articulación intergeneracional. Una particular modulación entre la "anacronía mítica" y "heterocronía transmedia" es lo que los autores detectan en el caso de la campaña de la expresidenta Cristina Fernández de Kirchner en 2011. La "ilusión del contacto sin mediaciones" entre políticos y ciudadanos en épocas de redes sociales permeó las campañas, pero lo cierto es que, concluyen los autores, no hubo en realidad una explotación de las potencialidades de los lenguajes digitales.

Asimismo, la sociosemiótica se encuentra con la filosofía en el artículo de Silvia Tabachnik, docente e investigadora de la Universidad Autónoma Metropolitana de México (UAM). Su tema es las mutaciones en la construcción del acontecimiento en épocas de Internet. A partir de un corpus de archivos audiovisuales, Tabachnikabordala mediatización delos eventos de Ayotzinapa de septiembre de 2014 -la desaparición de estudiantes-, postulando no ya una "construcción" del acontecimiento como planteaba Verón en los 80 del siglo pasado, sino una "conjura" destinada a diluir y neutralizar su impacto, convirtiéndolo en un episodio más de la narco-novela mexicana cotidiana.

La noción de acontecimiento planteada por Tabachnik se despega de lo narrativo-mediático a partir de una interrogación desdela clásica formulación foucaultiana que enlaza con el ánimo deconstructivo derridiano de la artefactualidad mediática. La problemática del testimonio en tanto experiencia inconmensurable del sobreviviente se encuentra, asimismo, demandado en el análisis de Tabachnik, quien acude al régimen de la parresía como una ética del sujeto que se constituye, citando a Badiou (1999), no en un régimen de verdad, sino en una "fidelidad al acontecimiento".

El artículo de Pablo Francescutti -investigador de la Universidad Rey Juan Carlos y del Grupo de Estudios de Semiótica dela Cultura (GESC), dirigido por Jorge Lozano en la Universidad Complutense de Madrid, España- analiza los cambios ocurridos en el documento a partir de la prensa electrónica. Su tema es el rol primordial que ocupó el documento en el desarrollo del periodismo moderno en tanto estrategia de veridicción y construcción de un efecto de objetividad periodística.

Francescutti presenta un estudio del caso de los cables de las embajadas de Estados Unidos en la cobertura de la filtración conocida como Cablegate, realizada por el diario español El País, destacando que la "función probatoria" del documento resultó fortalecida en su tránsito al periodismo online y que las bases de datos se han posicionado de manera central, proyectando al periódico como un archivo. La interdependencia entre documento y archivo puede pensarse, tal como plantea Francescutti citando a Lozano (2013), como una 
relación de contenido/continente. La dimensión de "continente" adquiere, en el Cablegate, un lugar central, ya que la revela a Wikileaks como interpretante del Gran Archivo. El análisis de Francescutti pondera así la dimensión semiótica de las interfaces y sus regímenes de creencia como vector analítico, ya que dan cuenta de las modulaciones de las expectativas sobre la veracidad y la objetividad de los contenidos digitales.

Eldocumento, en tanto prueba material en la construcción del acontecimiento, tuvo, según constata el autor, una mutación cuantitativa a partir dela fotocopiadora en la década del 70 del siglo pasado, produciéndose un salto significativo con la digitalización en cuanto a capacidad de archivo y difusión. La filtración masiva, a fines de 2010, de documentos clasificados, conocida como Cablegate, marcó una importante mutación, ya que por primera vez una primicia fue difundida en las ediciones online de los principales diarios internacionales antes que en las impresas, de este modo se posesionó al periodismo electrónico en el centro de la escena mediática. Se advierte, en la formulación de Francescutti, una "semiótica del documento" que cuestiona la naturaleza de "soporte material” en épocas de digitalización, instaurando nuevos regímenes de verdad. Retomandola perspectiva deLatour(2002), Francescuttiplanteaaldocumento comoente híbridoalcualsele atribuyen funciones humanas. La opacidad delas interfaces es su consecuencia. El ánimo deconstructivo del planteo tiende, de tal modo, a enfatizar "el poder digital de hacer ver y de no hacerse ver".

También ligado a los dilemas del periodismo en la mediatización actual, y colocado plenamente en el debate sobre el fin delos medios de masas, el artículo de Daniel Mazzone, de la Universidad ORT Uruguay, aborda las mutaciones del formato diario, que se juegan entre la periodicidad y la simultaneidad. Postulando la disolución del concepto de diario por los medios gráficos online, Mazzone advierte el cierre de un ciclo y la consolidación de un nuevo ecosistema informacional, en el cual entra en crisis, asimismo, el clásico "contrato de comunicación" ante la "hibridación" de las audiencias.

Por su parte, Mariana Busso -investigadora de la UNR, Argentina- aborda la problemática de la construcción de identidad en las redes sociales mediante el estudio de grupos de migrantes en Facebook. En tal sentido, y al amparo de la noción de migración mediatizada como articulación identitaria compleja, la autora analiza la construcción de colectivos de pertenencia comunitaria a partir de novedosas gestiones de lo íntimo. El importante aparato argumentativo generado por Busso para este análisis incluye, además de las consideraciones semióticas, reconocidas fuentes provenientes de los estudios culturales, tales como las reflexiones sobre identidad de, en este caso, Stuart Hall (2003 y 2010); y marca, sin duda, una agenda de temas insoslayables a la hora de comprender los agenciamientos identitarios en épocas de redes sociales.

Otro modo de entrar, desdela semiótica, al estudio dela mediatización, es el que encontramos en el texto de Armando Monzón Nieves, Máster en Comuni- 
cación por la Universidad Nacional Autónoma de México (UNAM) y docente en la Universidad Tecnológica Latinoamericana en Línea (UTEL), México. Tanto su tarea investigativa y docente como su trabajo en la edición de libros de textos impresos y digitales en distintas editoriales mexicanas y extranjeras, se advierten en el recorrido planteado en el artículo, el cual se ocupa, desde un enfoque general que se ubica en la semiótica de la cultura, de la problemática de la enseñanza en el nivel de educación básica en escuelas privadas mexicanas. En tal escenario, los dispositivos electrónicos ocupan un lugar relevante y son, al mismo tiempo, un espacio de tensión entre profesores y estudiantes ya plenamente alfabetizados en los lenguajes digitales. Sobre esa base, Monzón Nieves delimita claramente un diagnóstico de la educación privada en México, teniendo como uno de sus principales problemas el tema dela mediatización. El autor plantea, como claves analíticas de dicha problemática, un enfoque metafórico que sitúala experiencia con los dispositivos desde una perspectivalúdica y de exploración ociosa, recuperando autores de distintas tradiciones que, en su conjunto, interpelan de una manera peculiar a la perspectiva semiótica.

A los fines de cerrar, provisoriamente, este estado de la cuestión, podemos decir que los estudios de mediatizaciones se encuentran, a pesar de su breve historia, ya consolidados. Los artículos presentados en este volumen pueden considerarse una muestra representativa de los términos en que se desarrollan los debates actuales sobre el tema: atravesadas por un ánimo eminentemente transdisciplinar, se dibujan de manera porosa las fronteras entre tres perspectivas, que nombramos como la escuela nórdica, la escuela de Toronto y la escuela sociosemiótica. Apelar a la nominación de "escuelas" puede ocasionar, sin duda, un escenario polémico, lo cierto es que implica, simultáneamente, una operación destinada a la contribución de la legitimación del campo de estudios en mediatizaciones.

La revista InMediaciones de la Comunicación se coloca, con este volumen, en el medio de estos desafíos. Será tarea deloslectores continuar la controversia.

\section{REFERENCIAS}

Badiou, A. (1999). El ser y el acontecimiento. Buenos Aires: Manantial. En Tabachnik, S. en este volumen.

Berman, M. (2013). La construcción de un género radiofónico: el radioteatro (Tesis doctoral. Inédita). Doctorado en Ciencias Sociales, Facultad de Ciencias Sociales, Universidad de Buenos Aires. 
Calvo, E. (2015) Anatomía política del twitteren Argentina. Tuiteando\#Nissman. Buenos Aires: Capital Intelectual. En Baggiolini, L. Castro Rojas, S. en este volumen.

Derrida, J. \& Stiegler, B. (1998). Ecografías de la televisión. Entrevistas filmadas, Buenos Aires: Eudeba. En Tabachnik, S. en este volumen.

Foucault, M. (2004). Discurso y verdad en la Antigua Grecia. Barcelona: Paidós. En Tabachnik, S. en este volumen.

Hall, S. (2003). ¿Quién necesita 'identidad’? En Hall, S. \& du Gay, P. (comps.), Cuestiones de identidad cultural (pp. 13-39). Buenos Aires: Amorrortu. En Busso, M. en este volumen.

Hall, S. (2010). La cuestión de la identidad cultural. En Sin garantías: Trayectorias y problemáticas en estudios culturales (pp. 363-404). Bogotá: Envión Editores. En Busso, M. en este volumen.

Hjarvard, S. (2013). The Mediatization of Culture and Society. New York: Routledge. En Sbardelotto, M. en este volumen.

Krotz,F.(2007).The Meta-Process of Mediatization' as a ConceptualFrame.En GlobalMedia and Communication, 3. En Sbardelotto, M. en este volumen.

Krotz, F. (2014). Mediatization as a mover in modernity: Social and cultural change in the context of media change. En K. Lundby (ed.), Mediatization of communication (pp. 131-161). Berlin: De Gruyter Mouton. En Hjarvard, S. en este volumen.

Latour, B. (2002). La Fabrique du Droit, Paris: La Decouverte. En Francescutti, P. en este volumen.

Lozano, J. (2013). Wikileaks, un archivo. En Lozano y Díaz (eds.), Vigilados. Wikileaks o las nuevas fronteras de la información (pp. 33-50). Madrid: Biblioteca Nueva. En Francescutti, P. en este volumen.

Santaella,L.(2003).Daculturadasmídiasà cibercultura:oadventodopóshumano.EnRevista Famecos: midia, cultura y tecnología, 10 (22),pp. 23-32. En Stra, S. en este volumen.

Van Dijck, J. (2013). La cultura de la conectividad. Una historia crítica de las redes sociales. Buenos Aires: Siglo XXI. En Fernández, J. L. en este volumen.

Verón, E. (1987). Construir el acontecimiento. Buenos Aires: Gedisa. En Tabachnik, S. en este volumen.

Verón, E. (1996). La palabra adversativa. Observaciones sobre la enunciación política En Verón, E. et al., El discurso político. Lenguajes y acontecimientos (pp. 2-12). Buenos Aires: Hachette. En Baggiolini y Castro Rojas en este volumen.

Verón, E. (2014) “Teoria da midiatização: uma perspectiva semioantropológica e algumas de suas consequências". En MATRIZes, 8 (1), pp. 13-19. En Sbardelotto, M. en este volumen. Doi: http://dx.doi.org/10.11606/issn.1982-8160.v8ilp13-19 